\title{
Aspectos físico-químicos e microbiológicos do queijo tipo coalho comercializado em estados do nordeste do Brasil
}

\author{
Physical-chemical and microbiological aspects of the \\ rennet cheese sold in the Northeast States of Brazil
}

\author{
Andréa Zilá Barroso de Sousa ${ }^{1 *}$, Maria Rociene Abrantes ${ }^{1}$, Sidnei Miyoshi Sakamoto', \\ Jean Berg Alves da Silva', Patrícia de Oliveira Lima', Renata Nayhara de Lima', \\ Manuella de Oliveira Cabral Rocha', Yanna Deysi Bandeira Passos ${ }^{1}$
}

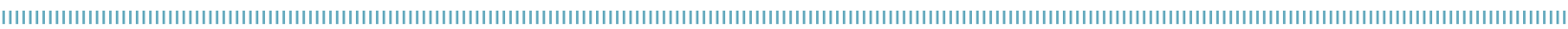

RESUMO: O objetivo deste trabalho foi avaliar o perfil das características físico-químicas e microbiológicas dos queijos de coalho comercializados em seis estados do nordeste brasileiro. Foram realizadas análises físico-química e microbiológica de 104 amostras de queijo de coalho comercializadas nos estados de Pernambuco, Piauí, Ceará, Rio Grande do Norte, Sergipe e Paraíba, sendo 50 amostras inspecionadas e 54 sem inspeção. Não foi observada diferença significativa $(p>0,05)$ para os parâmetros físico-químicos entre as amostras. De acordo com os parâmetros legislativos, nas 104 amostras analisadas de queijos tipo coalho, verificaram-se que 100 (96,15\%) estavam fora dos limites para Staphylococcus coagulase positiva; 32 amostras (31\%) também não seguiam a padronização exigida para coliformes termotolerantes; e, em apenas uma amostra do total, constatou-se a presença de Salmonella sp. Não foi observada diferença significativa $(p>0,05)$ entre as amostras com e sem inspeção para as análises microbiológicas. A semelhança encontrada na avaliação dos parâmetros físico-químicos do queijo de coalho entre os estados avaliados demonstra uniformidade no processamento desse produto. Altos níveis de contaminação por agentes patogênicos, como o Staphylococcus coagulase positiva e coliformes termotolerantes, além da presença de Salmonella sp., demonstram que o consumo de queijo de coalho pode representar risco à saúde dos consumidores.

PALAVRAS-CHAVE: coliformes termotolerantes; $\mathrm{pH}$; Salmonella sp.; Staphylococcus coagulase positiva; umidade.

\begin{abstract}
The objective of this study was to evaluate the physical-chemical and microbiological profile of the rennet cheese sold in six states in northeastern Brazil. Physical-chemical and microbiological analyses of 104 samples of rennet cheese sold in the states of Pernambuco, Piauí, Ceará, Rio Grande do Norte, Paraíba and Sergipe were analyzed, being 50 samples inspected and 54 without inspection. There was no significant difference ( $p>0.05$ ) for physical-chemical parameters between samples. In accordance with the parameters of the legislation, in the 104 examined samples of rennet cheese, it was observed that 100 (96.15\%) were outside the limits for Staphylococcus coagulase positive; 32 samples $(31 \%)$ did not follow the standardization required for coliforms; and only one sample showed the presence of Salmonella sp. There was no significant difference ( $\mathrm{p}>0.05)$ between samples with and without inspection for microbiological analyses. The similarity found in the assessment of physicalchemical parameters of rennet cheese between the evaluated states demonstrates uniformity in the processing of this product. High levels of contamination by pathogens such as Staphylococcus coagulase positive and thermo-tolerant coliforms, as well as the presence of Salmonella sp., demonstrate that the consumption of rennet cheese may present a health risk for consumers.
\end{abstract}

KEYWORDS: thermo-tolerant coliform; pH; Salmonella sp.; Staphylococcus coagulase positive; humidity. 


\section{INTRODUÇÃO}

Entende-se por queijo de coalho aquele que se obtém pela coagulação do leite por meio do coalho ou outras enzimas coagulantes apropriadas, complementada ou náo pela ação de bactérias lácteas selecionadas, sendo comercializado normalmente com até dez dias de fabricação (Brasil, 2001a). O produto é típico da região Nordeste, local onde suas técnicas de produção provêm de tradiçóes enraizadas e persistem até hoje em todas as regióes produtoras. No entanto, a falta de critérios de qualidade da matéria prima e das técnicas de processamento permite que produtos de baixa qualidade cheguem ao mercado, tanto do ponto de vista higiênico-sanitário quanto da falta de padronizaçáo (NAssu et al., 2001a).

Apesar de a legislação brasileira estabelecer que o leite utilizado na fabricação de queijos deve ser submetido à pasteurização ou a tratamento térmico equivalente (BrAsIL, 1996), somente as unidades produtoras inspecionadas que promovem o tratamento térmico do leite. Em $85 \%$ dos casos, o leite utilizado na elaboração deste queijo não é pasteurizado (Nassu et al., 2001b), o que representa um risco em potencial para o consumidor devido à possibilidade de veiculação de micro-organismos patogênicos, como a Salmonella sp. e o Staphylococcus, e micro-organismos do grupo coliforme. Outro fator agravante é o fato de o queijo coalho ser, na maioria das vezes, consumido cru, ou seja, sem nenhum tratamento químico ou térmico (DuARTe et al., 2005).

Atualmente, em função do grande consumo, já existe uma legislação nacional especifica, por meio do Regulamento Técnico de Identidade e Qualidade de Produtos Lácteos, o qual estabelece os padrôes de identidade e os requisitos mínimos de qualidade que o queijo coalho deve cumprir para ser destinado ao consumo humano (Freitas Filho et al., 2012).

Tendo em vista a grande importância econômica e nutricional do queijo de coalho para a regiáo onde é produzido, este trabalho teve como objetivo avaliar a qualidade físico-química e microbiológica deste produto comercializado em diferentes estados da regiáo nordeste do Brasil.

\section{MATERIAL E MÉTODOS}

Foram coletadas 104 amostras de queijo de coalho de seis estados da regiáo nordeste: Sergipe (20), Ceará (24), Piauí (10), Rio grande do Norte (20), Paraíba (10) e Pernambuco (20), sendo 54 amostras de queijo de coalho artesanal e 50 amostras de queijo de coalho industrial sob registro do Serviço de Inspeçẫo Estadual (SIE) e Federal (SIF). Os queijos foram adquiridos em supermercados e mercados locais.

As amostras coletadas foram acondicionadas em caixas isotérmicas e transportadas ao Laboratório de Inspeção de Produtos de Origem Animal (LIPOA), da Universidade
Federal Rural do Semiárido (UFERSA), onde foram submetidas a análises físico-químicas e microbiológicas logo após sua chegada. O tempo de transporte entre a coleta e o laboratório variou de 1 a 24 horas, dependendo da distância do local de coleta. Os queijos possuíam embalagens distintas e aqueles com inspeção encontravam-se dentro do prazo de validade. Os que tinham inspeção federal ou estadual estavam embalados a vácuo, e os comprados em mercados públicos, ou seja, queijos frescos artesanais sem inspeção, foram dispostos sobre balcôes ou acondicionados em refrigeradores, sendo obtidos com material do estabelecimento. Destes últimos não havia a informação sobre o tempo em que eles estavam expostos e à venda.

As análises físico-químicas foram: umidade, atividade de água, $\mathrm{pH}$ e acidez, realizadas segundo as especificaçóes dos Métodos Analíticos Oficiais para Controle de Produtos de Origem Animal e seus Ingredientes, publicados pelo Laboratório Nacional de Referência Animal (Lanara, 1981).

Já as análises microbiológicas contaram com a verificação de Número Mais Provável (NMP) de coliformes a $45^{\circ} \mathrm{C}$, Samonella sp. e Staphylococcus coagulase positiva, seguindo recomendação constante na Instruçáo Normativa no 62 , de 26 de agosto de 2003, do Ministério da Agricultura, Pecuária e Abastecimento (BrAsIL, 2003).

As variáveis qualitativas foram avaliadas pelo teste do qui-quadrado, utilizando para tal o programa Epi Info (Dean et al., 1994). Os dados de parâmetros físico-químicos foram submetidos à análise de variância (ANOVA) e ao teste de comparação de médias $t$ de Student ( $5 \%$ de confiança), com auxílio do programa de estatística versão 6.0 (STATsoft Inc., 2004).

\section{RESULTADOS E DISCUSSÃO}

Os resultados encontrados para os parâmetros físico-químicos (umidade, $\mathrm{pH}$, atividade da água e acidez) das amostras de queijos de coalho podem ser visualizados na Tabela 1 , que demonstra que não houve diferença significativa $(\mathrm{p}>0,05)$ entre os estados para nenhum dos parâmetros avaliados.

Para o parâmetro potencial hidrogeniônico $(\mathrm{pH})$, as amostras com e sem inspeção apresentaram médias de 5,68 e 5,18, respectivamente. Os valores encontrados neste trabalho foram semelhantes aos de outros estudos sobre a análise físico-química do queijo de coalho. Freitas Filho et al. (2009) encontraram valores para $\mathrm{pH}$ de 5,27 - 5,85 para queijos de coalho artesanais no estado de Pernambuco. Araujo; Nassu (2002), ao estudarem o $\mathrm{pH}$ do queijo de coalho industrializado e artesanal, verificaram que o parâmetro variou de 5,10 a 5,80.

$\mathrm{O}$ pH é considerado uma determinação importante para caracterizar queijos devido à sua influência na textura, na atividade microbiana e na maturação, já que ocorrem reaçóes químicas que são catalisadas por enzimas provenientes do coalho e da microbiota, que dependem do $\mathrm{pH}$. 
Tabela 1. Valores médios das análises físico-químicas do queijo de coalho comercializado em seis estados da região nordeste de acordo com tipo de produção, com inspeção ou sem inspeção.

\begin{tabular}{|c|c|c|c|c|c|c|c|}
\hline \multirow{2}{*}{ Variável } & & \multicolumn{6}{|c|}{ Estados } \\
\hline & & SE & CE & PI & RN & PB & PE \\
\hline \multirow{2}{*}{$\mathrm{pH}$} & $\mathrm{QCl}$ & 5,68 & 6,21 & 6,23 & 6,20 & 6,04 & 5,56 \\
\hline & QSI & 5,18 & 6,02 & 6,20 & 5,90 & 6,22 & 5,54 \\
\hline \multirow{2}{*}{ Umidade (\%) } & $\mathrm{QCI}$ & 21,00 & 16,67 & 14,38 & 24,08 & 20,43 & 21,56 \\
\hline & QSI & 29,38 & 25,33 & 15,00 & 17,86 & 21,33 & 26,36 \\
\hline \multirow{2}{*}{$\mathrm{Aa}$} & $\mathrm{QCl}$ & 0,91 & 0,91 & 0,91 & 0,91 & 0,92 & 0,96 \\
\hline & QSI & 0,89 & 0,91 & 0,91 & 0,92 & 0,91 & 0,96 \\
\hline \multirow{2}{*}{ Acidez (\%) } & $\mathrm{QCl}$ & 0,74 & 0,49 & 0,16 & 0,37 & 0,33 & 0,42 \\
\hline & QSI & 1,01 & 0,64 & 0,12 & 0,40 & 0,31 & 0,60 \\
\hline
\end{tabular}

Médias seguidas de letras diferentes na mesma linha diferem entre si pelo teste de Tukey ( $>$ > 0,05); Aa: Atividade de Água; QCI: queijo com inspeção; QSI: queijo sem inspeção; SE: Sergipe; CE: Ceará; PI: Piauí; RN: Rio Grande do Norte; PB: Paraíba; PE: Pernambuco.

De acordo com Munck (2004), o queijo tem um pH alto $(5,7$, quando se usa fermento, chegando a 6,5 , quando não se usa fermento), o que cria condiçôes favoráveis para o desenvolvimento das bactérias contaminantes. Os resultados observados para este parâmetro no presente trabalho indicam que a qualidade da matéria prima e do processamento utilizado na produção do queijo de coalho são semelhantes entre os estados e independem de fiscalizaçáo.

Quanto à umidade, os queijos de coalho avaliados apresentaram variação de 14,38 a $24,08 \%$ para os produtos com inspeção, e de 15 a 29,38\% para os de fabricação artesanal, sem diferenças significativas entre estes $(p>0,05)$, caracterizando, assim, queijo de umidade baixa $(<39 \%)$. Os valores de umidade encontrados no presente trabalho diferiram dos resultados obtidos por Silva et al. (2010), que observaram teores de umidade variando de 45,5 a $51,5 \%$, podendo ser caracterizado como queijo de média $(39 \%<$ umidade $<46 \%)$ a alta umidade $(46 \%<$ umidade $<55 \%$ ). Já Silva et al. (2006) encontraram valores médios de $40,28 \%$ no total de 11 amostras de queijo de coalho comercializados na cidade de Natal (RN). Todas as amostras avaliadas nessa pesquisa ficaram em desacordo com os níveis de umidade estabelecidos no Regulamento Técnico de Identidade e Qualidade de Queijo de Coalho que varia de 39 a 55\% (Brasil, 2001a), fato possivelmente atribuído à falta de padronizaçáo na elaboração do queijo.

Segundo Freitas Filho et al. (2009), a umidade interfere na atividade de água $(\mathrm{Aa})$ e nas açôes metabólicas de micro-organismos ao longo da maturação, com suas possíveis consequências no $\mathrm{pH}$, na textura, no sabor e no aroma. Segundo Oliveira (1981), o teor de umidade varia muito e está correlacionado ao tempo de conservação do queijo. Os mais desidratados são mais duros e mais conservados, mesmo em condiçóes adversas. NAssu et al. (2001a) afirmaram que a diferença de umidade deve-se a variaçóes na matéria prima utilizada e ao processamento em si, ou seja, a formação e o manuseio da coalhada afetam sua habilidade de reter gordura e umidade, o que influencia a composição centesimal, além do tempo de prensagem, os quais, segundo esses autores, diferem muito entre os produtores e podem influenciar o teor de umidade do queijo.

A Aa variou de 0,911 a 0,963 para os queijos de coalho com inspeção, e 0,892 para os queijos de coalho sem inspeção, sem diferenças significativas $(p>0,05)$. Resultados semelhantes foram observados por ANDRADE (2006), que encontrou valores de Aa variando de 0,944 $\pm 0,001$ a 0,979 $\pm 0,002$. $\mathrm{O}$ referido autor também constatou que a média Aa para as amostras industrializadas foi superior à das amostras artesanais. Valores elevados Aa tornam os queijos mais suscetíveis ao elevado desenvolvimento microbiano.

A acidez percentual expressa em ácido lático variou de 0,16 a $0,74 \%$ de ácido lático para os queijos com inspeção, e de 0,12 a $1,01 \%$ para os queijos de produção artesanal, sem diferenças significativas entre ambos $(p>0,05)$. A acidez decorrente da produçấo de ácido lático a partir da degradação da lactose pelas bactérias tem influência direta no $\mathrm{pH}$ e na expulsão de soro da massa durante a fabricação e na fase inicial da cura. Em estudo realizado por Perez (2005), utilizando amostras de queijo de coalho industrializadas adquiridas na cidade de Campinas (SP), as médias obtidas para acidez foram similares às deste estudo para as amostras industriais, variando de 0,18 a $0,50 \%$.

Embora não haja na legislação valores de referência para as análises de $\mathrm{Aa}$, acidez e $\mathrm{pH}$ do queijo de coalho, os valores encontrados neste trabalho foram semelhantes aos citados na literatura. Já os valores de umidade se apresentaram abaixo do exigido na legislação; no entanto, esta característica confere ao mesmo maior durabilidade. 
Nas 104 amostras de queijos tipo coalho analisadas verificou-se que $100(96,15 \%)$ estavam fora dos limites aceitos pela legislação (Agência Nacional de Vigilância Sanitária ANVISA) para Staphylococcus coagulase positiva; 32 amostras (31\%) também não seguiam a padronização exigida para coliformes termotolerantes; apenas uma amostra do apresentou a presença de Salmonella sp. (Tabela 2). Não houve diferença $(p>0,05)$ nas contagens de Staphylococcus coagulase positiva e coliformes termotolerantes entre as amostras com e sem inspeção. No entanto, é importante destacar as contagens elevadas para as amostras industrializadas, que são fiscalizadas por órgãos oficiais e deveriam obedecer aos requisitos mínimos de elaboração dos produtos. Os queijos que possuem SIE e SIF têm suas instalaçóes inspecionadas por fiscais da Secretaria de Agricultura do Estado ou por fiscais do Ministério da Agricultura, Pecuária e Abastecimento (MAPA), e devem seguir os padróes de qualidade exigidos por esses órgãos, enquanto os queijos artesanais não são submetidos à inspeção. Vários estudos têm classificado o queijo de coalho, principalmente o artesanal, como impróprio para consumo humano devido ao elevado nível de contaminação por bactérias patogênicas (Borges et al., 2003; Feitosa et al., 2003; BRUNo et al., 2005). A literatura faz referência a inúmeros relatos de surtos e casos esporádicos de doenças transmitidas por alimentos (DTA) atribuídos ao consumo de queijos contaminados por Staphylococcus coagulase positiva, tornando esta espécie uma das mais importantes a serem estudadas. No Ceará, por exemplo, o Núcleo de Epidemiologia da Secretária de Saúde do Estado do Ceará notificou um surto de intoxicação estafilocócica atribuído ao consumo de queijo coalho (CEARÁ, 2004).

Todos os estados apresentaram contaminação elevada para Staphylococcus coagulase positiva no queijo tipo coalho. Além disso, do total de amostras analisadas, 99 (95,19\%) estavam acima do padrão exigido pela legislaçáo brasileira (Brasil, 2001b), que estabelece como tolerância para amostra indicativa por análise de $5 \times 10^{2} \mathrm{UFC} / \mathrm{g}$ para contagem de
Staphylococcus coagulase positiva. Os valores encontrados neste trabalho variaram de 2,5 a $25 \times 10^{5} \mathrm{UFC} / \mathrm{g}$. Observaram-se que $98,15 \%$ das amostras de queijos de coalho artesanais analisadas estavam fora do padrão, e que $92 \%$ das amostras de queijos coalho industrial com inspeção, estadual ou federal, também estavam fora da legislação vigente.

As vias de contaminação dos queijos podem ser o leite, o manipulador e o ambiente de processamento. No leite cru, a principal fonte de contaminação provém da mastite bovina, na qual Staphylococcus coagulase positiva é o principal agente etiológico. No entanto, os estudos realizados nas indústrias revelam que a contaminação cruzada após a pasteurização do leite seria fonte importante de contaminação dos queijos por patógenos. A legislação brasileira determina que todos os queijos elaborados industrialmente devem ser fabricados com leite pasteurizado, e que esse processo é eficiente na destruição de estafilococos. Assim, supóe-se que a contaminação do queijo de coalho industrializado tenha ocorrido nas etapas pós-processo, ou pode ter sido resultante de uma pasteurizaçáo náo eficiente do leite (Borges et al., 2003; Feitosa et al., 2003; Bruno et al., 2005). Em razão de estafilococos serem comumente encontrados nas fossas nasais, garganta e pele de portadores humanos, estudos epidemiológicos de surtos de intoxicação estafilocócica têm apontado os manipuladores como a principal fonte de contaminação do alimento (AssumpÇão et al., 2003). Outro agravante é a forma de armazenamento durante a comercialização, principalmente dos queijos de coalho artesanais que são expostos a temperaturas inadequadas (temperatura ambiente) e somente no final do dia são armazenados sob refrigeração. Segundo a Instrução Normativa no 30 (Brasil, 2001a), o queijo de coalho deve manter-se a uma temperatura não superior a $12^{\circ} \mathrm{C}$ durante sua conservaçáo e comercialização. No entanto, esse limite de temperatura náo é eficiente, pois segundo Adams; Moss (1997) o S. aureus é capaz de produzir toxinas entre 10 e $45^{\circ} \mathrm{C}$, tendo como faixa de temperatura ótima entre 35 e $40^{\circ} \mathrm{C}$.

Tabela 2. Parâmetros microbiológicos de queijos de coalho com inspeção e sem inspeção de acordo com padrão da ANVISA.

\begin{tabular}{|c|c|c|c|c|c|c|c|}
\hline \multirow{2}{*}{ Variáveis } & & \multicolumn{6}{|c|}{ Estados } \\
\hline & & SE & CE & PI & RN & PB & PE \\
\hline \multirow{2}{*}{$\begin{array}{l}\text { Staphylococcus } \\
\text { coagulase positiva }\end{array}$} & $\mathrm{QCl}$ & $1 / 7$ & $6 / 6$ & $2 / 8$ & $0 / 13$ & $0 / 7$ & $1 / 9$ \\
\hline & QSI & $0 / 13$ & $0 / 18$ & $0 / 2$ & $0 / 7$ & $0 / 3$ & $1 / 11$ \\
\hline \multirow{2}{*}{$\begin{array}{l}\text { Coliformes } \\
\text { Termotolerantes }\end{array}$} & $\mathrm{QCI}$ & $2 / 7$ & $6 / 6$ & $8 / 8$ & $13 / 13$ & $7 / 7$ & $0 / 9$ \\
\hline & QSI & $3 / 13$ & $17 / 18$ & $2 / 2$ & $4 / 7$ & $3 / 3$ & $7 / 11$ \\
\hline \multirow{2}{*}{ Salmonella } & $\mathrm{QCI}$ & - & - & - & - & - & - \\
\hline & QSI & - & - & - & - & + & - \\
\hline Total de amostras & & 20 & 24 & 10 & 20 & 10 & 20 \\
\hline
\end{tabular}

+: presente; -: ausente; QCI: queijo com inspeção; QSI: queijo sem inspeção; SE: Sergipe; CE: Ceará; PI: Piauí; RN: Rio Grande do Norte; PB: Paraíba; PE: Pernambuco. 
A ocorrência de coliformes fecais em queijo de coalho, principalmente nos artesanais, em níveis superiores aos permitidos pela legislação também foi observada em outros trabalhos (Florentino; Martins, 1999; Paiva; Cardonha, 1999; Bruno et al., 2005). A reduzida população desses micro-organismos indica baixo nível de contaminação fecal, o que pode ser atribuído à qualidade da matéria prima ou às condiçóes de processamento dos queijos. Por outro lado, Feitosa et al. (2003), Paiva; Cardonha (1999) e Mendes et al. (2001) têm relatado a ocorrência de altos níveis de coliformes fecais em queijos coalho.

Dentre as 104 amostras de queijos de coalho analisadas, $32(31 \%)$ estavam acima do padrão exigido pela legislação brasileira (BrAsıL, 2001b), que estabelece como limite de tolerância para amostra indicativa de coliformes termotolerantes $5 \times 10^{2} \mathrm{NMP} / \mathrm{mL}$ (CT). Os valores encontrados neste trabalho variaram de 3 a $11 \times 10^{2} \mathrm{NMP} / \mathrm{mL}$. Observaram-se que 18 (33\%) amostras de queijos de coalho artesanais analisadas apresentaram-se fora do padrão e, dentre as amostras de queijos coalho industriais com inspeção, 14 (28\%), sem diferenças significativas entre as amostras com e sem inspeção $(\mathrm{p}>0,05)$. Esse índice de contaminação se deve às más condiçóes de higiene durante o processo de fabricação e distribuição dos produtos ao consumidor, agravadas pela ausência de pasteurização.

Do total de 104 amostras analisadas, apenas em uma foi detectada a presença de Salmonella, diferindo de outros trabalhos de pesquisa para detecção de Salmonella em queijo de coalho. Em estudo realizado por Paiva; Cardonha (1999), esse micro-organismo não foi detectado em queijo de coalho produzido no Rio Grande do Norte. Já Florentino; Martins (1999) detectaram a presença de Salmonella em $30 \%$ das amostras de queijo de coalho artesanal produzidas em várias regióes do estado da Paraíba. Mendes et al. (2001) encontram Salmonella em 73,3\% das amostras de queijos de coalho produzidos e comercializados em Recife, oriundos de 15 municípios de Pernambuco. Já Duarte et al. (2005) detectaram a presença desse micro-organismo em 5,5\% das amostras avaliadas nesse mesmo estado.

Sabe-se que a Salmonella mantém-se viável em queijo contaminado por longo período de tempo (Modi et al., 2001), o que ressalta a importância do controle da qualidade microbiológica do produto, visto que a legislação brasileira estabelece a ausência desta bactéria em alimentos (Brasil, 2001b). A Salmonella é potencialmente capaz de provocar infecção alimentar, e a presença dessa bactéria classifica os queijos como produtos impróprios para consumo.

A contaminação com a Salmonella pode estar relacionada a diferentes fontes, porém, a pasteurização é capaz de eliminá-la, o que pode justificar que a única amostra positiva para esta bactéria se encontrava exatamente entre as amostras de queijo de coalho artesanal. Mesmo essa baixa porcentagem pode representar risco à saúde da população, uma vez que o queijo de coalho é um alimento típico regional e facilmente acessível às diversas classes sociais.

\section{CONCLUSÕES}

A semelhança encontrada na avaliação dos parâmetros físico-químicos do queijo de coalho entre os estados avaliados demonstra uniformidade no processamento desse produto. No entanto, evidencia-se a necessidade de uma legislação de valores de referência para essas variáveis.

O consumo de queijo de coalho deve ser motivo de preocupação para as autoridades da região onde eles é produzido devido ao alto nível de contaminaçáo por agentes patogênicos, como o Staphylococcus coagulase positiva e coliformes termotolerantes, além da presença de Salmonella sp., representando risco à saúde dos consumidores.

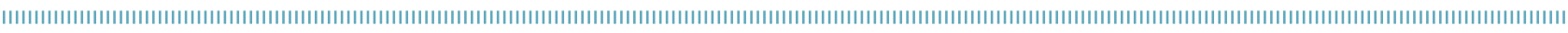

\section{REFERÊNCIAS}

ANDRADE, A.A. Estudo do perfil sensorial, físico-químico e aceitação de queijo de Coalho produzido no estado do Ceará. 2006. 138 f. Dissertação (Mestrado) - Universidade Federal do Ceará, Fortaleza, 2006.

ADAMS, M.R.; MOSS, M.O. Microbiologia de los alimentos. Zaragoza (España): Editorial Acribia, S. A. 1997. p.258-264. 464p.

ARAUJO, R.S.; NASSU, R.T. Caracterização físico-química de queijo de Manteiga, queijo de Coalho e Manteiga da Terra, produzidos no estado do Rio Grande do Norte e do Ceará. Revista Higiene Alimentar, São Paulo, v.16, n.97, p.70-75, 2002.
ASSUMPÇÃO, E.G.; PICCOLI-VALLE, R.H.; HIRSCH, D.; ABREU, L.R. Fontes de contaminação por Staphylococcus aureus na linha de processamento de queijo prato. Arquivo Brasileiro de Medicina Veterinária e Zootecnia, v.55, n.3, 2003.

BORGES, M.F.; FEITOSA, T.; NASSU, R.T.; MUNIZ, C.R.; AZEVEDO, E.H.F; FIGUEIREDO, E.A.T. Microrganismos patogênicos e em queijo de Coalho produzido no Ceará, Brasil. Boletim do Centro de Pesquisa e Processamento de Alimentos, v.2 1, n. 1, p.31-40, 2003.

BRASIL. MINISTÉRIO DA AGRICULTURA, PECUÁRIA E ABASTECIMENTO. Instrução Normativa no 30, de 26 de junho de 2001 . Diário oficial da União. Brasília, 16 de julho de 2001 a. 
BRASIL. MINISTÉRIO DA SAÚDE. AGÊNCIA NACIONAL DE VIGILÂNCIA SANITÁRIA. Resolução RDC $n^{\circ} 12$, de 2 de janeiro de 2001. Diário Oficial da União. Brasília, 2 de janeiro de 2001b.

BRASIL. MINISTÉRIO DA AGRICULTURA, PECUÁRIA E ABASTECIMENTO. Instrução Normativa n $^{\circ} 62$, de 26 de agosto de 2003. Diário Oficial da União. Brasília, 18 de setembro de 2003.

BRASIL. MINISTÉRIO DA AGRICULTURA, PECUÁRIA E ABASTECIMENTO. Portaria n 146, de 7 de março de 1996. Diário Oficial da União. Brasília, 11 de março de 1996.

BRUNO, L.M.; FEITOSA, T.; NASSU, R.T.; CARVALHO, J.D.G.; ANDRADE, A.A. Avaliação microbiológica de queijos de coalho artesanais e industrializados comercializados em Fortaleza, CE. Revista do Instituto de Laticínios Cândido Tostes, v.60, n.345, p.217-220, 2005.

CEARÁ. SECRETARIA DA SAÚDE DO ESTADO DO CEARÁ. Núcleo de Epidemiologia. Célula de Vigilância Epidemiológica. Informe anual de surtos das doenças transmitidas por alimentos. Fortaleza, 2004.

DEAN, A.G.; DEAN, J.A.; COULOMBIER, D.; BRENDEL, K.A.; SMITH, D.C.; BURTON, A.H. EPI Info, Version 6.0: a word processing database and statistics program for epidemiology on microcomputer. [computer software]. Atlanta, Georgia: Center of Disease Control and Prevention, 1994.

DUARTE, D.A.M.; SCHUCH, D.M.T.; SANTOS, S.B.; Ribeiro, A.R.; Vasconcelos, A.M.M.; Silva, J.V.D.; DA MOTA, R.A. Pesquisa de Listeria monocytogenes e microrganismos indicadores higiênicosanitários em queijo-coalho produzido e comercializado no estado de Pernambuco. Arquivo do Instituto Biológico, v.72, p.297-302, 2005.

FEITOSA, T.; BORGES, M.F.; NASSU, R.T.; AZEVEDO, E.H.F.; MUNIZ, C.R. Pesquisa de Salmonella sp., Listeria sp. e microrganismos indicadores higiênico-sanitário em queijo de coalho produzido no Estado do Rio Grande do Norte. Ciência e Tecnologia de Alimentos, v.23, p.162-165, 2003.

FLORENTINO, E.R.; MARTINS, R.S. Características microbiológicas do "queijo de coalho" produzido no estado da Paraíba. Higiene Alimentar, São Paulo, v.13, n.59, p.43-48, 1999.

FREITAS FILHO, J.R.; SOUZA FILHO, J.S.; OLIVEIRA, H.B.; ANGELO, J.H.B.; BEZERRA, J.D.C. Avaliação da qualidade do queijo "coalho" artesanal fabricado em Jucati - PE. Extensio: Revista Eletrônica de Extensão, v.6, n.8, p.35-49, 2009.

LANARA. LABORATÓRIO NACIONAL DE REFERENCIA ANIMAL. Métodos analíticos oficiais para controle de produtos de origem animal e seus ingredientes: /I-Métodos físicos e químicos. Brasília: Ministério da Agricultura, 1981.
MENDES, E.S.; LIMA, E.C.; NUMERIANO, A.K.M.; COELHO, M.I.S.N. Staphylococcus aureus, Salmonella sp. e coliformes em queijo de "coalho" comercializados em Recife. Higiene Alimentar, v.13, n.66/67, p.122-126, 2001.

MODI, R.; HIRVI, Y.; HILL, A.; GRIFFITHS, M.W. Effect of phage on survival of Salmonella enteritidis during manufacture and storage of cheddar cheese made from raw and pasteurized milk. Journal Food Protection, Ames, v.64, n.7, p.927-933, 2001.

MUNCK, A.V. Queijo de Coalho - Princípios básicos da fabricação (Palestra). Revista do Instituto de Laticínios Cândido Tostes, Juiz de Fora, v.59, n.339, p.13-15, 2004.

NASSU, R.T.; LIMA, J.R; BASTOS, M.S.R.; MACEDO, B.A.; LIMA, M.H.P. Diagnóstico das condições de processamento de queijo de coalho e manteiga da terra no estado do Ceará. Higiene alimentar, São Paulo, v.15, n.89, p.28-36, 2001 a.

NASSU, R.T.; ARAUJO, R.S.; BORGES LIMA, J.R.; MACEDO, B.A.; LIMA, M.H.P.; BASTOS, M.S.R. Diagnóstico das condições de processamento de produtos regionais derivados do leite no estado do Ceará. Boletim de Pesquisa e Desenvolvimento 1. EMBRAPA Disponível em: < http://www. cnpat.embrapa.br/publica/pub/BolPesq/p\%26d_1.pdf >. Acesso em: 10 jun. 2012.

OLIVEIRA, J.S. Queijo: fundamentos tecnológicos. São Paulo: Secretaria da Indústria, Comércio, Ciência e Tecnologia / Fundação Tropical de Pesquisas e Tecnologia, 1981.233 p.

PAIVA, M.S.D.; CARDONHA, A.M.S. Queijo de Coalho artesanal e industrializado produzidos no Rio grande do Norte. Revista Higiene Alimentar, São Paulo, v.13, n.61, p.33-37, 1999.

PEREZ, R.M. Perfil sensorial, físico-químico e funcional de queijo de coalho comercializado no município de Campinas. 2005. 122 f. Dissertação (Mestrado) - Universidade Estadual de Campinas, Campinas, 2005.

SILVA, A.E.A.; SANTOS, N.N.; SEABRA, L.M.J.; DAMASCENO, K.S.F.S.C. Quantificação de lipídios, cinzas e umidade de queijos tipo manteiga e Coalho comercializados na cidade de Natal, RN. Higiene Alimentar, v.20, n.145, p.101-104, 2006.

SILVA, M.C.D.; RAMOS, A.C.S.; MORENO, I.; MORAES, J.O. Influência dos procedimentos de fabricação nas características físico-químicas, sensoriais e microbiológicas de queijo de Coalho. Revista do Instituto Adolfo Lutz, São Paulo, v.69, n.2, p.214-221, 2010.

STATSOFT. Statistica: data analysis software system, version 7 . Tulsa, 2004. Disponível em: <http://www.statsoft.com>. Acesso em: 25 jul. 2011. 